\title{
Quantitative Genetic Analysis of the Metabolic Syndrome in Hispanic Children
}

\author{
NANCY F. BUTTE, ANTHONY G. COMUZZIE, SHELLEY A. COLE, NITESH R. MEHTA, GUOWEN CAI, \\ MARIA TEJERO, RAUL BASTARRACHEA, AND E. O'BRIAN SMITH
}

\begin{abstract}
Department of Pediatrics [N.F.B., N.R.M., E.O.S.], USDA/ARS Children's Nutrition Research Center, Baylor College of Medicine, Houston, Texas 77030, Department of Genetics [A.G.C., S.A.C., G.C., M.T., R.B.], Southwest Foundation for Biomedical Research, San Antonio, Texas 78245
\end{abstract}

\begin{abstract}
Childhood obesity is associated with a constellation of metabolic derangements including glucose intolerance, hypertension, and dyslipidemia, referred to as metabolic syndrome. The purpose of this study was to investigate genetic and environmental factors contributing to the metabolic syndrome in Hispanic children. Metabolic syndrome, defined as having three or more metabolic risk components, was determined in 1030 Hispanic children, ages 4-19 y, from 319 families enrolled in the VIVA LA FAMILIA study. Anthropometry, body composition by dual energy $\mathrm{x}$-ray absorptiometry, clinical signs, and serum biochemistries were measured using standard techniques. Risk factor analysis and quantitative genetic analysis were performed. Of the overweight children, $20 \%$, or $28 \%$ if abnormal liver function is included in the definition, presented with the metabolic syndrome. Odds ratios for the metabolic syndrome were significantly increased by body mass index z-score and fasting serum insulin; independent effects of sex, age, puberty, and body composition were not seen. Heritabilities $\pm \mathrm{SE}$ for waist circumference, triglycerides (TG), HDL, systolic blood pressure (SBP), glu-
\end{abstract}

\section{ABSTRACT}

cose, and alanine aminotransferase (ALT) were highly significant. Pleiotropy (a common set of genes affecting two traits) detected between SBP and waist circumference, SBP and glucose, HDL and waist circumference, ALT and waist circumference, and TG and ALT may underlie the clustering of the components of the metabolic syndrome. Significant heritabilities and pleiotropy seen for the components of the metabolic syndrome indicate a strong genetic contribution to the metabolic syndrome in overweight Hispanic children. (Pediatr Res 58: 1243-1248, 2005)

$\quad$ Abbreviations
ALT, alanine aminotransferase
BMI, body mass index
CVD, cardiovascular disease
FM, fat mass
NHANES, National Health and Nutrition Examination Survey
SBP, systolic blood pressure
T2D, type 2 diabetes
TG, triglycerides

Childhood obesity in the United States has steadily increased in the past two decades according to NHANES, especially among Hispanic children $(1,2)$. The prevalence of overweight, defined as $\geq 95$ th BMI percentile, was $>20 \%$ among Mexican-American children. Childhood obesity is associated with several metabolic and endocrine derangements including glucose intolerance, hypertension, and dyslipidemia that predispose to early development of CVD and T2D (3). This constellation of metabolic derange-

Received April 5, 2005; accepted June 8, 2005.

Correspondence: N.F. Butte, Ph.D., Children's Nutrition Research Center, 1100 Bates St., Houston, TX 77030; e-mail: nbutte@ bcm.tmc.edu

This work is a publication of the U.S. Department of Agriculture (USDA)/Agricultural Research Service (ARS) Children's Nutrition Research Center, Department of Pediatrics, Baylor College of Medicine, and Texas Children's Hospital, Houston, TX.

This project was funded with federal funds from the National Institutes of Health (Grant R01 DK59264) and from USDA/ARS under Cooperative Agreement 58-6250-51000-037. The contents of this publication do not necessarily reflect the views or policies of the USDA, nor does mention of trade names, commercial products, or organizations imply endorsement by the U.S. government.

DOI: 10.1203/01.pdr.0000185272.46705.18 ments has been defined in adults as the metabolic syndrome. According to the National Cholesterol Education Program (NCEP) Adults Treatment Plan (ATP) III, the metabolic syndrome is defined as having three or more of the following risk factors: abdominal obesity, raised TG, low HDL cholesterol, elevated blood pressure, or glucose intolerance (4). Although abnormal liver function is not conventionally considered among the constellation of risk factors for the metabolic syndrome, it most likely shares common molecular pathway(s) and may contribute independently to the pathophysiology of CVD and T2D and lead to fatty liver disease (5). Abnormal liver function thus may be considered as part of the constellation of metabolic derangements, even in children. In severely obese adults, the metabolic syndrome was strongly correlated with steatosis, fibrosis, and cirrhosis of the liver (5). Although there is no generally accepted clinical definition of the metabolic syndrome in children, its prevalence has been estimated based on the ATP III definition modified for developmental changes in waist circumference, blood pressure, and blood lipids (6-8). 
This constellation of metabolic derangements associated with obesity arises as a result of complex interactions between an individual's genetic predisposition and environmental factors $(9,10)$. The metabolic, physiologic, and genetic mechanisms underlying the clustering of the components of the metabolic syndrome have been studied in adults (11-17) but not in children.

Here within, we investigated genetic and environmental factors contributing to the metabolic syndrome in a large cohort of Hispanic children participating in the VIVA LA FAMILIA study that was designed to genetically map childhood obesity in approximately 300 nuclear Hispanic families. Metabolic syndrome was defined as having three or more of the following metabolic risk factors: abdominal obesity, low HDL, hypertriglyceridemia, high blood pressure, and/or impaired fasting glucose. Our family-based study design allowed for the first time quantitative genetic analyses of metabolic syndrome to be conducted in a pediatric population. The specific aims of these analyses were 1) to estimate the percent of children with the metabolic syndrome in this cohort of Hispanic children; 2) to determine the effects of sex, age, and puberty on the metabolic syndrome; 3 ) to determine the impact of BMI z-score, body composition, and insulin resistance on the components of the metabolic syndrome; 4) to estimate the genetic contribution (heritability) for each component of the metabolic syndrome; and 5) to estimate genetic correlations between components of the metabolic syndrome to test for pleiotropy (shared gene effects) underlying this constellation of risk factors in Hispanic children.

\section{METHODS}

Study Design and Subjects. Genetic and environmental factors affecting the components of the metabolic syndrome were investigated in 1030 children enrolled in the VIVA LA FAMILIA study that was designed to genetically map childhood obesity in the Hispanic population. Each family was ascertained on an overweight proband between the ages 4 and $19 \mathrm{y}$ using a bivariate ascertainment scheme [i.e. overweight $\geq 95$ th percentile for BMI (18) and $\geq 85$ th percentile for FM $(19,20)]$. Once identified, the overweight proband and all siblings, 4-19 y of age, and their parents were invited to the Children's Nutrition Research Center for a tour and full explanation of the study. All children and their parents gave written informed consent or assent. The overweight proband and all siblings were characterized for body size, body composition, and phenotypes associated with the development of obesity. The protocol was approved by the Institutional Review Board for Human Subject Research for Baylor College of Medicine and Affiliated Hospitals.

Anthropometry and Body Composition. Body weight to the nearest $0.1 \mathrm{~kg}$ was measured with a digital balance and height to the nearest $1 \mathrm{~mm}$ was measured with a stadiometer. Body composition was determined by dualenergy x-ray absorptiometry (DXA) using a Hologic Delphi-A whole-body scanner (Delphi-A, Hologic, Inc., Waltham, MA). Total body estimates of FM and fat free mass (FFM), as well as truncal FM were obtained.

Clinical Signs. Blood pressure, heart rate, and temperature were taken in triplicate using a DINAMAP Vital Signs Monitor (8100T, Critikon, Inc., Tampa, FL). The child was seated quietly for at least $5 \mathrm{~min}$ before measurement. The arm was supported at heart level and the appropriate cuff size used. Tanner stages of sexual maturation based on pubic hair and breast and penis development, illustrated with drawings, were by self-report $(21,22)$.

Fasting Blood Biochemistries. A fasting blood sample was drawn for biochemical determinations. Fasting serum concentrations of glucose, TG, total cholesterol, and HDL were measured by enzymatic-colorimetric techniques using the GM7 Analyzer (Analox Instruments, Lundeburg, MA) and Microquant Platereader (Biotek Instruments, Winooski, VT). Glucose was assayed using glucose oxidase. TG were determined using lipase, glycerol kinase, glycerol phosphate oxidase, and peroxidase. Total cholesterol and HDL were determined using cholesterol esterase, cholesterol oxidase, and peroxidase $(23,24)$. Serum ALT was determined according to standard enzymatic assay procedures using a SPECTRAmaxPLUS spectrophotometer (Molecular Devices, Sunnyvale, CA) and reagents from ThermoDMA (Arlington, TX).

Definition of the Metabolic Syndrome. Metabolic syndrome was defined as having three or more of the following components:
1. Abdominal obesity (waist circumference $>90$ th percentile for age, sex, and ethnicity based on NHANES III) (25);

2. Low HDL (HDL $\leq 10$ th percentile for age and sex based on NHANES III) (26);

3. Hypertriglyceridemia (TG >90th percentile for ages 12-19 y and ethnicity based on NHANES III) (26);

4. High blood pressure (BP >90th percentile for height, age, and sex) (27);

5. Impaired fasting glucose (glucose $>100 \mathrm{mg} / \mathrm{dL}$ ) (28);

6. Abnormal liver function (ALT $>97.5$ th percentile for age and sex) (29).

Statistical Methods. Descriptive and risk factor analysis. ACCESS (version 9, Microsoft Corp, Seattle, WA) was used for database management. STATA (version 8.2, STAT Corp., College Station, TX) and MINITAB (version 13; Minitab Inc., State College, PA) were used for statistical analyses. Data are summarized as means $\pm \mathrm{SD}$. If the data were not normally distributed (kurtosis $>1.9$ ), a $\log$ transformation was performed and used in further analyses (30). Descriptive statistics, ordered logit regression, generalized estimating equations, and general least squares regression were performed. Model building began with Pearson correlation coefficients, followed by regression analysis to identify the independent contributions of age, sex, Tanner stage, insulin resistance, and body size and composition to the metabolic syndrome. In the case of collinearity, the strongest predictor was entered into the model. Dichotomous outcomes were coded 0 (i.e. absence of the metabolic syndrome) or 1 (i.e. presence of the metabolic syndrome). Odds ratio estimates, $\beta$-coefficients, and confidence intervals were obtained using ordered logit regression for ordinal outcomes and general estimating equations for dichotomous outcomes (logit link, binomial). To account for correlated data within families, family identification number was used as the cluster variable. Statistical significance was set at $p<0.05$.

Quantitative genetic analysis. Univariate quantitative genetic analysis was used to partition the total phenotypic variance $\left(\sigma_{\mathrm{P}}^{2}\right)$ of a trait into additive genetic $\left(\sigma_{\mathrm{G}}^{2}\right)$ and environmental $\left(\sigma_{\mathrm{E}}^{2}\right)$ components:

$$
\sigma_{\mathrm{P}}^{2}=\sigma_{\mathrm{G}}^{2}+\sigma_{\mathrm{E}}^{2}
$$

The environmental component includes factors such as diet and physical activity, measurement errors, and any genetic factor that is not additive. The additive heritability $\left(\mathrm{h}^{2}\right)$ of a trait represents the portion of the total phenotypic variance accounted for by the additive genetic variance:

$$
\mathrm{h}^{2}=\sigma_{\mathrm{G}}^{2} / \sigma_{\mathrm{P}}^{2}
$$

To determine the $p$ value of the heritability, a null model in which the additive genetic variance $\left(\sigma_{\mathrm{G}}^{2}\right)$ for the trait equals zero is compared with another model, where the $\sigma_{\mathrm{G}}^{2}$ is estimated using maximum likelihood method. Twice the difference between the natural logarithm likelihood of the two models asymptotically distributes as a $1 / 2: 1 / 2$ mixture of a $\chi^{2}$ distribution with one degree of freedom (31).

Bivariate analyses were conducted to partition the phenotypic relationships $\left(\rho_{\mathrm{p}}\right)$ between two traits into genetic $\left(\rho_{\mathrm{G}}\right)$ and environmental correlations $\left(\rho_{\mathrm{E}}\right)$ :

$$
\rho_{p}=\rho_{G} \sqrt{ } h^{2}{ }_{1} \sqrt{h^{2}}{ }_{2}+\rho_{E} \sqrt{ }\left(1-h^{2}{ }_{1}\right) \sqrt{ }\left(1-h^{2}{ }_{2}\right)
$$

In this equation, $\mathrm{h}_{1}{ }_{1}$ and $\mathrm{h}_{2}{ }_{2}$ correspond to the heritabilities of the two traits. The bivariate phenotype is considered a linear function of the individual's phenotypic values, the population means, the additive genetic values, and environmental effects (32). A model with the genetic correlation constrained to zero is compared with another model where all parameters are estimated. To test for complete pleiotropy, a model where the genetic correlation is constrained to 1.0 is compared with an alternative model where all parameters are estimated. Twice the difference of logarithm likelihood of the two models asymptotically yields a distribution of $\chi^{2}$ with one degree of freedom. Evidence of pleiotropy (a common set of genes influencing more than one trait) is indicated by a genetic correlation significantly different from 0 .

The segenetic analyses have been implemented in the computer program SOLAR 2.0 (Southwest Foundation for Biomedical Research, San Antonio, TX) (33). Age, sex, $\mathrm{age}^{2}$, and the interactions of age $\times$ sex and $\operatorname{age}^{2} \times$ sex were simultaneously estimated in these analyses. Since our cohort was selected based on a proband who was an overweight child, an ascertainment correction is required and performed in SOLAR to obtain unbiased parameter estimates in the variance component model. In the variance component method, ascertainment corrections condition on the trait value of the proband (34).

\section{RESULTS}

A total of 1030 children and their biologic parents $(n=600)$ from 319 Hispanic families were included in the final VIVA LA FAMILIA cohort. The average family size was 5.3 (range, 2-10). The age distribution of the children was 14,45 , and $41 \%$ in the age brackets 4-5 y, 6-11 y, and 12-19 y, respectively. Tanner stage distribution was $51,14,16,12$, and $7 \%$ in stages $1-5$, respectively. The majority $(82 \%)$ of the children participating in 
the VIVA LA FAMILIA study are first-generation Americans of Mexican and Central American descent. The majority of the parents were either overweight (34\%) or obese (57\%). A family history of diabetes (68\%), CVD (60\%), and hypertension (78\%) was reported for the parents and/or grandparents. Previously undiagnosed T2D was detected in four children from different families and T1D was present in one child. For the present analyses, these five children have been excluded.

Anthropometry, body composition, and the components of the metabolic syndrome are presented in Table 1. Eighteen percent of the children were at risk of overweight (85th $\leq$ BMI $<$ 95th percentile). Fifty-one percent of the children were classified as overweight (BMI $\geq 95$ th percentile). Of the overweight children, $47 \%$ were above the 99.0th BMI percentile with $\mathrm{z}$-scores ranging from 2.3 to 4.5 .

SBP was significantly higher in boys $(p=0.001)$ and overweight children $(p=0.001)$. Diastolic blood pressure (DBP) was within normal limits for all children. Waist circumference differed by overweight status and sex (two-way interaction, $p=0.04$ ), with the highest values in overweight boys. Fasting HDL was lowest among overweight children $(p=0.001)$. Fasting plasma glucose was slightly higher in boys $(p=0.002)$ and overweight children $(p=0.001)$. Fasting ALT was higher in boys $(p=0.001)$ and overweight children $(p=0.001)$.

The impact of sex, age, BMI z-score, body composition, and insulin resistance on the components of the metabolic syndrome was explored (Table 2). Because of high correlation between BMI z-score and other body composition parameters, only BMI z-score and truncal FM as an indicator of central obesity were used in the linear regression models. Bivariate analysis revealed that all the components of the metabolic syndrome were correlated with BMI $\mathrm{z}$-score, truncal FM, and insulin ( $p=0.001)$. Together, sex, age, fasting serum insulin, BMI z-score, and truncal FM explained 43, $37,18,15$, and $22 \%$ of the variance in SBP, TG, HDL, serum glucose, and serum ALT, respectively, in the linear regression models. The degree of obesity (BMI z-score), insulin resistance and central adiposity (truncal FM) was associated with an increase in the components of the metabolic syndrome.

The percentage of children with components of the metabolic syndrome and the percentage of children with zero, one, two, or three or more components of the metabolic syndrome are presented in Table 3. Metabolic syndrome, defined as three or more components, was present in $20 \%$ of overweight boys and $19 \%$ of overweight girls. The metabolic syndrome was present in $11 \%$ of children with BMI z-scores above 1.64 (95th BMI percentile) and in $30 \%$ of children with BMI z-scores above 2.33 (99th BMI percentile). Including serum ALT in the definition, the prevalence of the metabolic syndrome defined using three out of six components was $28 \%$ in overweight boys and $27 \%$ in overweight girls. Defined as such, the metabolic syndrome was present in $16 \%$ of the children with BMI z-scores above 1.64 (95th BMI percentile) and in 40\% with BMI z-scores above 2.4 (99th BMI percentile).

Risk factors influencing the number of components and presence of the metabolic syndrome were explored in Table 4, and in Figures 1 and 2. Sex, age, fasting serum insulin, BMI z-score, and truncal FM were associated independently with the number of components of the metabolic syndrome. Sexual maturation estimated by Tanner stages did not have an independent effect on the metabolic syndrome. The estimated odds ratios for the presence of metabolic syndrome were significant for fasting serum insulin and BMI z-score, but not for sex, age, or truncal FM. Similar results were obtained for the number of components and presence of the metabolic syndrome, including fasting serum ALT.

Given the near absence of the metabolic syndrome in nonoverweight subjects, the impact of risk factors on the presence of the metabolic syndrome in the overweight children only was examined. Controlling for sex and age, the estimated odds ratios for the effects of BMI z-score $(3.04,3.64)$ and fasting serum insulin $(2.11,3.12)$ on the metabolic syndrome computed using the five and six components, respectively, were significant and similar to the values for the entire sample.

Table 1. Characterization of children enrolled in VIVA LA FAMILIA study

\begin{tabular}{|c|c|c|c|c|}
\hline & $\begin{array}{l}\text { Nonoverweight boys } \\
\quad(n=228)\end{array}$ & $\begin{array}{l}\text { Overweight boys } \\
\quad(n=281)\end{array}$ & $\begin{array}{l}\text { Nonoverweight girls } \\
\quad(n=276)\end{array}$ & $\begin{array}{l}\text { Overweight girls } \\
\quad(n=240)\end{array}$ \\
\hline Age (y) & $11 \pm 4^{*}$ & $11 \pm 4$ & $10 \pm 5$ & $11 \pm 4$ \\
\hline Weight $(\mathrm{kg}) \dagger$ & $43 \pm 20^{\mathrm{a}}$ & $71 \pm 30^{\mathrm{b}}$ & $38 \pm 18^{\mathrm{a}}$ & $64 \pm 25^{\mathrm{c}}$ \\
\hline BMI $\left(\mathrm{kg} / \mathrm{m}^{2}\right) \S$ & $20 \pm 4$ & $31 \pm 7$ & $20 \pm 4$ & $30 \pm 6$ \\
\hline BMI z-score $\ddagger$ & $0.69 \pm 0.76$ & $2.39 \pm 0.43$ & $0.59 \pm 0.82$ & $2.22 \pm 0.33$ \\
\hline FFM $(\mathrm{kg}) \ddagger$ & $33.5 \pm 15.6$ & $42.0 \pm 15.9$ & $26.3 \pm 10.8$ & $36.6 \pm 12.5$ \\
\hline Truncal FM $(\mathrm{kg}) \ddagger$ & $3.8 \pm 2.6$ & $11.9 \pm 5.8$ & $4.9 \pm 3.5$ & $12.7 \pm 6.1$ \\
\hline $\mathrm{SBP}(\mathrm{mm} \mathrm{Hg}) \ddagger$ & $107 \pm 12 *$ & $113 \pm 11$ & $102 \pm 10$ & $110 \pm 8$ \\
\hline Waist circumference $(\mathrm{cm}) \dagger$ & $66 \pm 12^{\mathrm{a}}$ & $89 \pm 17^{\mathrm{b}}$ & $62 \pm 10^{\mathrm{c}}$ & $83 \pm 15^{\mathrm{d}}$ \\
\hline Fasting serum TG $(\mathrm{mg} / \mathrm{dL}) \S$ & $85 \pm 46$ & $123 \pm 58$ & $86 \pm 42$ & $120 \pm 53$ \\
\hline Fasting HDL cholesterol $(\mathrm{mg} / \mathrm{dL}) \S$ & $50 \pm 12$ & $44 \pm 10$ & $50 \pm 12$ & $43 \pm 9$ \\
\hline Fasting plasma glucose $(\mathrm{mg} / \mathrm{dL}) \ddagger$ & $91 \pm 8$ & $94 \pm 8$ & $89 \pm 8$ & $93 \pm 8$ \\
\hline
\end{tabular}

* Mean $\pm \mathrm{SD}$.

$\dagger$ Controlling for age, significant two-way interaction between overweight status and sex $(p=0.04-0.001)$.

$\ddagger$ Controlling for age, significant main effects of overweight status and sex $(p=0.05-0.001)$.

$\S$ Controlling for age, significant main effect of overweight status $(p=0.001)$.

Significantly different mean values by posthoc Tukey testing are indicated by different superscripts. 
Table 2. Risk factors influencing the components of the metabolic syndrome in children enrolled in VIVA LA FAMILIA study evaluated simultaneously by linear regression $(n=1025)$

\begin{tabular}{|c|c|c|}
\hline Factor & $\beta$-coefficient $\pm \mathrm{SE}^{*}$ & $p$ Value (adjusted)* \\
\hline \multicolumn{3}{|l|}{ Systolic blood pressure } \\
\hline Sex & $-3.45 \pm 0.54$ & 0.001 \\
\hline Age & $1.20 \pm 0.10$ & 0.001 \\
\hline Ln fasting serum insulin & $2.70 \pm 0.54$ & 0.001 \\
\hline BMI z-score & $2.25 \pm 0.41$ & 0.001 \\
\hline Truncal FM & $0.04 \pm 0.09$ & $\begin{array}{c}0.61 \\
\text { Adj } r^{2}=0.43\end{array}$ \\
\hline \multicolumn{3}{|l|}{ Ln Serum triglycerides } \\
\hline Sex & $-0.01 \pm 0.02$ & 0.86 \\
\hline Age & $0.02 \pm 0.01$ & 0.001 \\
\hline Ln fasting serum insulin & $0.25 \pm 0.02$ & 0.001 \\
\hline BMI z-score & $0.06 \pm 0.02$ & 0.001 \\
\hline Truncal FM & $0.01 \pm 0.01$ & $\begin{array}{c}0.18 \\
\text { Adj } r^{2}=0.37\end{array}$ \\
\hline \multicolumn{3}{|l|}{ Serum HDL cholesterol } \\
\hline Sex & $-0.42 \pm 0.61$ & 0.49 \\
\hline Age & $-0.14 \pm 0.11$ & 0.19 \\
\hline Ln fasting serum insulin & $-1.99 \pm 0.63$ & 0.001 \\
\hline BMI z-score & $-1.94 \pm 0.48$ & 0.001 \\
\hline Truncal FM & $-0.30 \pm 0.10$ & $\begin{array}{c}0.002 \\
\text { Adj } r^{2}=0.18\end{array}$ \\
\hline \multicolumn{3}{|l|}{ Ln Serum glucose } \\
\hline Sex & $-0.022 \pm 0.005$ & 0.001 \\
\hline Age & $0.001 \pm 0.001$ & 0.47 \\
\hline Ln fasting serum insulin & $0.044 \pm 0.005$ & 0.001 \\
\hline BMI z-score & $0.009 \pm 0.004$ & 0.03 \\
\hline Truncal FM & $-0.002 \pm 0.001$ & $\begin{array}{c}0.05 \\
\text { Adj } r^{2}=0.15\end{array}$ \\
\hline \multicolumn{3}{|l|}{ Ln Serum ALT } \\
\hline Sex & $-0.20 \pm 0.04$ & 0.001 \\
\hline Age & $-0.04 \pm 0.01$ & 0.001 \\
\hline Ln fasting serum insulin & $0.28 \pm 0.04$ & 0.001 \\
\hline BMI z-score & $0.002 \pm 0.03$ & 0.93 \\
\hline Truncal FM & $0.02 \pm 0.01$ & $\begin{array}{c}0.001 \\
\text { Adj } r^{2}=0.22\end{array}$ \\
\hline
\end{tabular}

Sex is coded 1 male, 2 female; age (y), truncal FM (kg), ln fasting serum insulin $(\mu \mathrm{U} / \mathrm{mL})$. Risk factors influencing the components of the metabolic syndrome also were tested individually and yielded similar results, except for positive associations between SBP and ln serum TG with truncal FM; negative association between HDL cholesterol and age; positive associations between $\ln$ serum glucose and ALT with age; and positive association between $1 \mathrm{n}$ serum ALT and BMI z-score (all $p$ values $=0.001$ ).

$* \beta$-coefficients and $p$ values are presented for risk factors adjusted simultaneously for all other factors in the model. Adj $r^{2}$ is the percentage of variance explained with all factors in the model, i.e. sex, age, ln fasting serum insulin, BMI z-score, and truncal FM.

Heritabilities \pm SE for FM $\left(h^{2}=0.33 \pm 0.07\right)$, truncal FM $\left(h^{2}=0.31 \pm 0.08\right)$, waist circumference $\left(h^{2}=0.42 \pm 0.08\right)$, TG $\left(h^{2}=0.54 \pm 0.08\right), \mathrm{HDL}\left(h^{2}=0.64 \pm 0.07\right), \operatorname{SBP}\left(h^{2}=\right.$ $0.32 \pm 0.07)$, glucose $\left(h^{2}=0.62 \pm 0.08\right)$, insulin $\left(h^{2}=0.37\right.$ $\pm 0.08)$, and ALT $\left(h^{2}=0.28 \pm 0.08\right)$ were highly significant for these Hispanic children $\left(p=5.4 \times 10^{-5}\right.$ to $\left.3.0 \times 10^{-22}\right)$. Environmental correlations between the components of the metabolic syndrome were all highly significant, with the exceptions of SBP and glucose, and TG and glucose. The genetic correlations between the components of the metabolic syndrome are given in Table 5. Positive genetic correlations \pm SE also were seen between ALT and BMI z-score $\left(\rho_{\mathrm{G}}=0.41 \pm\right.$ $0.16)$ and insulin $\left(\rho_{\mathrm{G}}=0.68 \pm 0.16\right)$. All the genetic correlations were significantly different from 1.0.

\section{DISCUSSION}

Genetic and environmental contributions to the metabolic syndrome were established in a large cohort of Hispanic children participating in the VIVA LA FAMILIA study. Although the prevalence of the metabolic syndrome has been described in other pediatric studies $(6-8)$, this is the first family-based study in which heritabilities for the components of the metabolic syndrome could be estimated in Hispanic children. Although the genetics of the metabolic syndrome have been studied in adults (12-17), heritabilities are not necessarily transferable to children even in the same population, because the genetic expression and environmental influences may vary with age. Metabolic risk factor analysis conferred a central role for insulin resistance and severe obesity in the presentation of the metabolic syndrome in these Hispanic children.

The presentation of the metabolic syndrome in these overweight Hispanic children, as young as 4-5 y of age, confers serious health risks. The metabolic syndrome presented in $20 \%$ of the overweight Hispanic children using the five conventional components or in $28 \%$ if abnormal liver function was included in the definition of metabolic syndrome. As in adults, the metabolic syndrome in children and adolescents is largely confined to overweight individuals. These results are similar to the prevalence (28.7\%) estimated in overweight adolescents participating in NHANES III (6). In NHANES III, the metabolic syndrome was more common in boys than girls, and more frequent in MexicanAmericans and Caucasians than African Americans (6); age and Tanner stage did not significantly influence the prevalence of the metabolic syndrome. In another study of 126 overweight Hispanic children (8-13 y) with a family history of T2D (7), 22\% had one, $38 \%$ had two, and $30 \%$ had three or more components of the metabolic syndrome (7). As in the present study, insulin resistance was found to be a central contributor to the metabolic syndrome in overweight Hispanic children. The prevalence of the metabolic syndrome also increased with the severity of obesity, as also seen in a large multiethnic cohort of children (8). The metabolic syndrome appears to emerge when a child's predisposition for insulin resistance worsens with increased adiposity (35).

Our cohort was ascertained on an overweight proband and, therefore, obesity prevalence rates are not representative of Hispanic children in the United States. In the latest NHANES (2), 14.1-26.5\% of Mexican-American children had BMI values in the overweight range. Trends in the prevalence of overweight in Mexican-American youth showed a steady increase from 1982-1984 HHANES, 19881994 NHANES III to the latest 1999-2002 NHANES (2). In our cohort, $51 \%$ of the children were overweight; and $24 \%$ were above the 99th BMI percentile. By design, our cohort is enriched for genes and behaviors related to obesity, and therefore informative with respect to the metabolic consequences associated with childhood obesity. Given the strong family history of obesity, diabetes, CVD, and hypertension reported for these Hispanic children, the early presentation of the metabolic syndrome portends a poor prognosis. In NHANES III, Mexican-American adults had the highest ageadjusted prevalence (31.9\%) of the metabolic syndrome (36). Similarly, the age-adjusted prevalence was $26.6 \%$ in Mexican adults according to the NCEP-III definition (37).

The genetics underlying the clustering of the components of the metabolic syndrome have been studied in adults (12-17) but not 
Table 3. Percentage of children enrolled in VIVA LA FAMILIA study with the metabolic syndrome $(n=1025)$

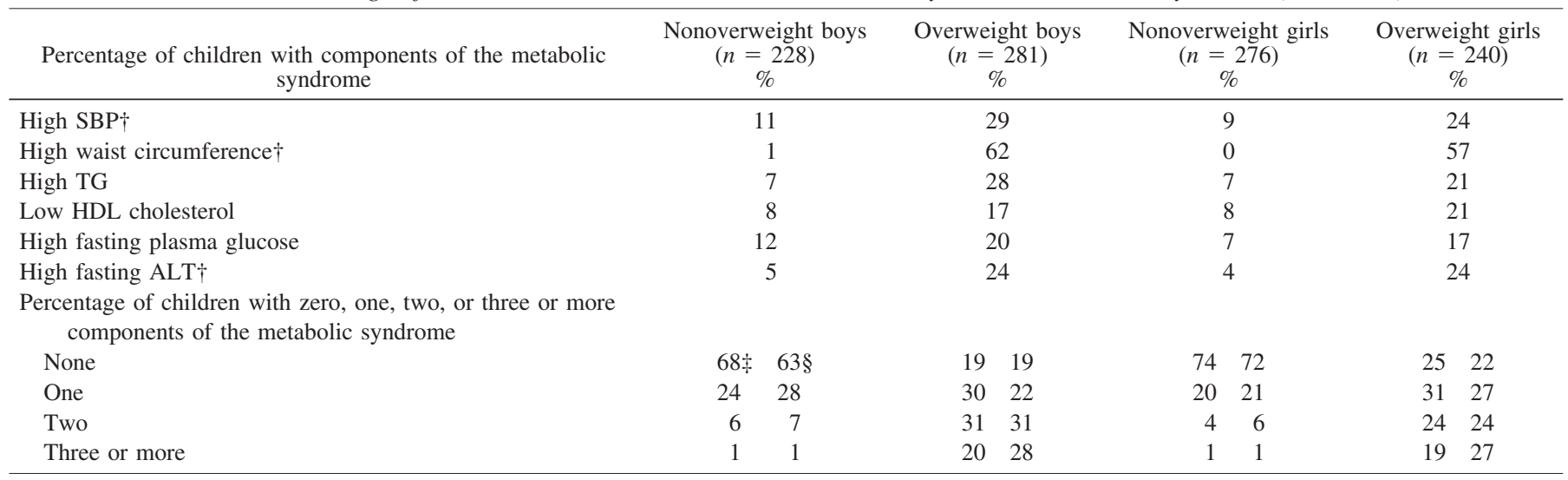

$\dagger$ Significant main effect of overweight status $(p=0.004-0.001)$.

$\ddagger$ Percentage computed with five conventional features of the metabolic syndrome.

$\S$ Percentage calculated with six features, including high fasting ALT.

Table 4. Factors influencing the number of components and presence of the metabolic syndrome

\begin{tabular}{|c|c|c|c|}
\hline Factor & $\begin{array}{l}\text { Odds } \\
\text { ratio* }\end{array}$ & $p$ Value* & $\begin{array}{l}95 \% \text { confidence } \\
\text { interval* }\end{array}$ \\
\hline \multicolumn{4}{|l|}{$\begin{array}{l}\text { Number of components of } \\
\text { the metabolic syndrome }\end{array}$} \\
\hline Sex & 0.64 & 0.002 & $0.48,0.85$ \\
\hline Age & 0.93 & 0.02 & $0.88,0.99$ \\
\hline Ln fasting serum insulin & 2.61 & 0.001 & $1.86,3.68$ \\
\hline BMI z-score & 2.05 & 0.001 & $1.52,2.76$ \\
\hline Truncal FM & 1.09 & 0.001 & $1.04,1.15$ \\
\hline \multicolumn{4}{|l|}{$\begin{array}{l}\text { Presence of the metabolic } \\
\text { syndrome }\end{array}$} \\
\hline Sex & 1.11 & 0.72 & $0.63,1.94$ \\
\hline Age & 0.99 & 0.87 & $0.85,1.15$ \\
\hline Ln fasting serum insulin & 2.48 & 0.001 & $1.49,4.11$ \\
\hline BMI z-score & 3.18 & 0.009 & $1.34,7.58$ \\
\hline Truncal FM & 1.06 & 0.19 & $0.97,1.17$ \\
\hline
\end{tabular}

Sex is coded 1 male, 2 female; age (y), truncal FM (kg), ln fasting serum insulin $(\mu \mathrm{U} / \mathrm{mL})$. Odds ratios for risk factors influencing the number of components and presence of the metabolic syndrome also were tested individually and yielded similar results, except for the odds ratio (1.06) of age on the presence of the metabolic syndrome $(p=0.02)$.

* Odds ratios, $p$ values, and $95 \%$ confidence intervals are presented for risk factors simultaneously adjusted for all other factors in the model.

in children. In adults there is evidence that the components of the metabolic syndrome share common genetic determinants. In the San Antonio Family Heart Study, a common set of genes influenced insulin levels and the components (12). Pleiotropy among the components of the metabolic syndrome was demonstrated in the Swedish Adoption/Twin Study of Aging (13). Genome scans also have provided evidence that genes may contribute to the clustering of risk factors for the metabolic syndrome $(13-15,17)$.

Heritability $\left(h^{2}\right)$ is defined as the relative proportion of the total phenotypic variance in a complex trait that is attributable to the additive effects of genes. Using quantitative genetic analysis, the total phenotypic variance for the components of the metabolic syndrome was decomposed into genetic and environmental components.

Significant heritabilities $\left(h^{2}\right)$ for BMI, FM, waist circumference, TG, HDL, SBP, fasting serum glucose, and ALT were demonstrated for this cohort of Hispanic children, indicating a significant portion of the variance in these components is due to additive genetic effects (9). The ascertainment of our cohort was

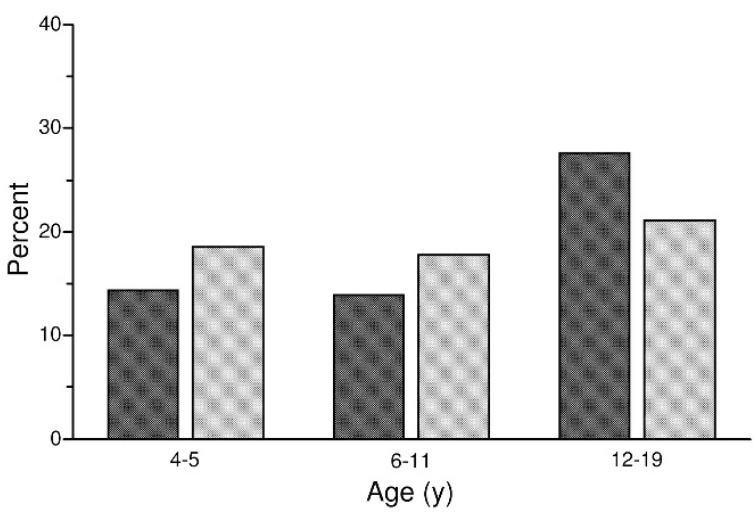

Figure 1. Percentage of overweight boys shown in dark gray bars $(n=281)$ and overweight girls shown in light gray bars $(n=240)$ in the VIVA LA FAMILIA study with the metabolic syndrome displayed as a function of age $(p=0.015)$.

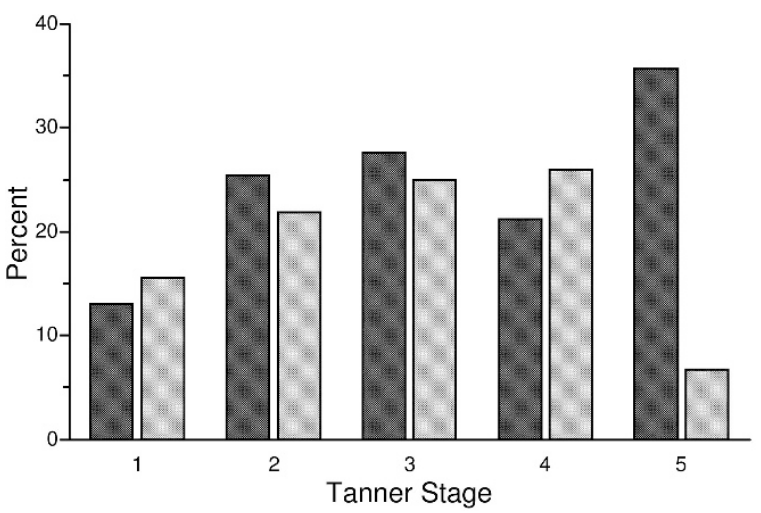

Figure 2. Percentage of overweight boys shown in dark gray bars $(n=281)$ and overweight girls shown in light gray bars $(n=240)$ in the VIVA LA FAMILIA study with the metabolic syndrome displayed as a function of Tanner stage $(p=0.07)$.

based on an obese proband, which theoretically could introduce bias into our estimate of heritability. However, we routinely correct for ascertainment bias in all our genetic analyses. Therefore, this estimate of heritability is generalizable to Hispanic children and, therefore, substantiates a strong genetic contribution to the components of the metabolic syndrome in Hispanic children.

Significant genetic correlations were detected among the components of the metabolic syndrome, suggesting pleiotropy may underlie the clustering of these components. Pleiotropy was seen between 
Table 5. Genetic $\left(\rho_{G}\right)$ correlations $\pm S E$ between the components of the metabolic syndrome in Hispanic children $(n=1025)$

\begin{tabular}{|c|c|c|c|c|c|}
\hline & SBP & Waist & TG & HDL-C & Glucose \\
\hline Waist & $0.33 \pm 0.09 *(0.002)$ & & & & \\
\hline TG & $0.07 \pm 0.12(0.57)$ & $0.17 \pm 0.10(0.11)$ & & & \\
\hline HDL-C & $0.08 \pm 0.11(0.42)$ & $-0.21 \pm 0.09(0.02)$ & $-0.05 \pm 0.11(0.62)$ & & \\
\hline ALT & $0.17 \pm 0.15(0.27)$ & $0.33 \pm 0.12(0.01)$ & $0.32 \pm 0.14(0.04)$ & $-0.05 \pm 0.14(0.73)$ & $-0.01 \pm 0.16(0.93)$ \\
\hline
\end{tabular}

* Genetic $\left(\rho_{\mathrm{G}}\right)$ correlations; adjusted for age, age ${ }^{2}$, and sex ( $p$ value in parenthesis).

SBP and glucose and adiposity-related traits (waist circumference and BMI z-score). The positive genetic correlations indicate that shared genes that augment glucose and adiposity also increase SBP. A negative genetic correlation between HDL and waist circumference was found, implying that the genes influencing these phenotypes have opposite effects on each trait. Positive genetic correlations were found between ALT and TG, insulin, waist circumference, as well as BMI z-score. Pleiotropy between BMI and insulin also has been reported in adult Hispanics (38) and in baboons (39). These observations suggest that the association between the metabolic syndrome and liver damage has a significant genetic component.

In conclusion, the complications of obesity in Hispanic children arise as a result of complex interactions between genetic and environmental factors. Significant heritabilities and pleiotropy seen for the components of the metabolic syndrome indicate a strong genetic contribution to the high prevalence of the metabolic syndrome in overweight Hispanic children.

Acknowledgments. The authors thank the families who participated in this study, and to acknowledge the contributions of Mercedes Alejandro and Marilyn Navarrete for study coordination, and Sopar Seributra for nursing and Theresa Wilson, Tina Ziba, Maurice Puyau, Firoz Vohra, Anne Adolph, Roman Shypailo, JoAnn Pratt, and Maryse Laurent for technical assistance.

\section{REFERENCES}

1. Ogden CL, Flegal KM, Carroll MD, Johnson CL 2002 Prevalence and trends in overweight among US children and adolescents, 1999-2000. JAMA 288:1728-1732

2. Flegal KM, Ogden CL, Carroll MD 2004 Prevalence and trends in overweight in Mexican-American adults and children. Nutr Rev 62:S144-S148

3. Must A, Strauss RS 1999 Risks and consequences of childhood and adolescent obesity. Int J Obes Relat Metab Disord 23:S2-S11

4. Grundy SM, Brewer HB Jr, Cleeman JI, Smith SC Jr 2004 Definition of metabolic syndrome: report of the National Heart, Lung, and Blood Institute/American Heart Association conference on scientific issues related to definition. Circulation 109:433-438.

5. Marceau P, Biron S, Hould FS, Marceau S, Simard S, Thung SN, Kral JG 1999 Liver pathology and the metabolic syndrome X in severe obesity. J Clin Endocrinol Metab $84: 1513-1517$

6. Cook S, Weitzman M, Auinger P, Nguyen M, Dietz WH 2003 Prevalence of a metabolic syndrome phenotype in adolescents: findings from the third National Health and Nutrition Examination Survey, 1988-1994. Arch Pediatr Adolesc Med 157:821-827

7. Cruz ML, Weigensberg MJ, Huang TT, Ball G, Shaibi GQ, Goran MI 2004 The metabolic syndrome in overweight Hispanic youth and the role of insulin sensitivity. J Clin Endocrinol Metab 89:108-113

8. Weiss R, Dziura J, Burgert TS, Tamborlane WV, Taksali SE, Yeckel CW, Allen K, Lopes M, Savoye M, Morrison J, Sherwin RS, Caprio S 2004 Obesity and the metabolic syndrome in children and adolescents. N Engl J Med 350:2362-2374

9. Comuzzie AG, Funahashi T, Sonnenberg G, Martin LJ, Jacob HJ, Black AE, Maas D, Takahashi M, Kihara S, Tanaka S, Matsuzawa Y, Blangero J, Cohen D, Kissebah A 2001 The genetic basis of plasma variation in adiponectin, a global endophenotype for obesity and the metabolic syndrome. J Clin Endocrinol Metab 86:4321-4325

10. Martin LJ, North KE, Dyer T, Blangero J, Comuzzie AG, Williams J 2003 Phenotypic, genetic, and genome-wide structure in the metabolic syndrome. BMC Genet 4:S95

11. Carmelli D, Cardon LR, Fabsitz R 1994 Clustering of hypertension, diabetes, and obesity in adult male twins: same genes or same environments? Am J Hum Genet 55:566-573

12. Mitchell BD, Kammerer CM, Mahaney MC, Blangero J, Comuzzie AG, Atwood LD, Haffner SM, Stern MP, MacCluer JW 1996 Genetic analysis of the IRS. Pleiotropic effects of genes influencing insulin levels on lipoprotein and obesity measures. Arterioscler Thromb Vasc Biol 16:281-288

13. Hong Y, Pedersen NL, Brismar K, de Faire U 1997 Genetic and environmental architecture of the features of the insulin-resistance syndrome. Am J Hum Genet 60:143-152
14. Arya R, Blangero J, Williams K, Almasy L, Dyer TD, Leach RJ, O'Connell P, Stern MP, Duggirala R 2002 Factors of insulin resistance syndrome-related phenotypes are linked to genetic locations on chromosomes 6 and 7 in nondiabetic MexicanAmericans. Diabetes 51:841-847

15. de Andrade M, Olswold C, Kardia SL, Boerwinkle E, Turner ST 2002 Multivariate linkage analysis using phenotypes related to the insulin resistance-metabolic disorder. 11th Annual Meeting of the International Genetic Epidemiology Society. Genet Epidemiol 23:275

16. Loos RJ, Katzmarzyk PT, Rao DC, Rice T, Leon AS, Skinner JS, Wilmore JH, Rankinen T, Bouchard C 2003 Genome-wide linkage scan for the metabolic syndrome in the HERITAGE Family Study. J Clin Endocrinol Metab 88:5935-5943

17. Cai G, Cole SA, Freeland-Graves JH, MacCluer JW, Blangero J, Comuzzie AG 2004 Principal component for metabolic syndrome risk maps to chromosome $4 p$ in Mexican Americans: the San Antonio Family Heart Study. Hum Biol 76:651-665

18. Must A, Dallal GE, Dietz WH 1991 Reference data for obesity: 85th and 95th percentiles of body mass index (wt/ht $\left.{ }^{2}\right)$ and triceps skinfold thickness. Am J Clin Nutr 53:839-846

19. Ellis KJ 1997 Body composition of a young, multiethnic, male population. Am J Clin Nutr 66:1323-1331

20. Ellis KJ, Abrams SA, Wong WW 1997 Body composition of a young, multiethnic female population. Am J Clin Nutr 65:724-731

21. Hofmann AD 1983 Adolescent Medicine. Addison-Wesley, Menlo Park, CA, pp 208-210

22. Speroff L, Glass RH, Kase NG 1989 Clinical Gynecologic Endocrinology and Infertility. Williams \& Wilkins, Baltimore, pp 426-427

23. Allain CC, Poon LS, Chan CS, Richmond W, Fu PC 1974 Enzymatic determination of total serum cholesterol. Clin Chem 20:470-475

24. Roeschlau P, Bernt E, Gruber W 1974 Enzymatic determination of total cholesterol in serum. Z Klin Chem Klin Biochem 12:226

25. Fernandez JR, Redden DT, Pietrobelli A, Allison DB 2004 Waist circumference percentiles in nationally representative samples of African-American, EuropeanAmerican, and Mexican-American children and adolescents. J Pediatr 145:439-444

26. Hickman TB, Briefel RR, Carroll MD, Rifkind BM, Cleeman JI, Maurer KR, Johnson CL 1998 Distributions and trends of serum lipid levels among United States children and adolescents ages 4-19 years: data from the Third National Health and Nutrition Examination Survey. Prev Med 27:879-890

27. 1996 Update on the 1987 Task Force Report on High Blood Pressure in Children and Adolescents: a working group report from the National High Blood Pressure Education Program. National High Blood Pressure Education Program Working Group on Hypertension Control in Children and Adolescents. Pediatrics 98:649-658

28. Expert Committee on the Diagnosis and Classification of Diabetes Mellitus 2002 Clinical practice recommendations. Diabetes Care 25:S1-S14724

29. Lockitch G, Halstead AC, Albersheim S, MacCallum C, Quigley G 1988 Age- and sex-specific pediatric reference intervals for biochemistry analytes as measured with the Ektachem-700 analyzer. Clin Chem 34:1622-1625

30. Blangero J, Williams JT, Almasy L 2001 Variance component methods for detecting complex trait loci. Adv Genet 42:151-181

31. Self SG, Liang KY 1987 Asymptotic properties of maximum likelihood estimators and likelihood ratio tests under nonstandard conditions. J Am Stat Assoc 82:605-610

32. Lange K, Boehnke M 1983 Extensions to pedigree analysis. IV. Covariance components models for multivariate traits. Am J Med Genet 14:513-524

33. Almasy L, Blangero J 1998 Multipoint quantitative-trait linkage analysis in general pedigrees. Am J Hum Genet 62:1198-1211

34. Amos CI, de Andrade M 2001 Genetic linkage methods for quantitative traits. Stat Methods Med Res 10:3-25

35. Haffner SM, Stern MP, Hazuda HP, Mitchell BD, Patterson JK 1990 Cardiovascular risk factors in confirmed prediabetic individuals. Does the clock for coronary heart disease start ticking before the onset of clinical diabetes? JAMA 263:2893-2898

36. Ford ES, Giles WH, Dietz WH 2002 Prevalence of the metabolic syndrome among US adults: findings from the Third National Health and Nutrition Examination Survey. JAMA 287:356-359

37. Aguilar-Salinas CA, Rojas R, Gomez-Perez FJ, Valles V, Rios-Torres JM, Franco A, Olaiz G, Rull JA, Sepulveda J 2004 High prevalence of metabolic syndrome in Mexico. Arch Med Res 35:76-81

38. Comuzzie AG, Blangero J, Mahaney MC, Haffner SM, Mitchell BD, Stern MP, MacCluer JW 1996 Genetic and environmental correlations among hormone levels and measures of body fat accumulation and topography. J Clin Endocrinol Metab 81:597-600

39. Tejero ME, Proffitt JM, Cole SA, Freeland-Graves JH, Cai G, Peebles KW, Cox LA, Mahaney MC, Rogers J, VandeBerg JL, Blangero J, Comuzzie AG 2004 Quantitative genetic analysis of glucose transporter 4 mRNA levels in baboon adipose. Obes Res $12: 1652-1657$ 